\title{
LA ENSEÑANZA DE LA HISTORIA EN LA PROVINCIA DE BUENOS AIRES: APORTES PARA LA CONSTRUCCIÓN DE UN BALANCE SOBRE SU RENOVACIÓN EN LA ESCUELA SECUNDARIA
}

O ENSINO DA HISTÓRIA NA PROVÍNCIA DE BUENOS AIRES: PARA UM BALANÇO SOBRE A RENOVAÇÃO NO ENSINO MÉDIO

HISTORY TEACHING IN THE PROVINCE OF BUENOS AIRES: TOWARDS A BALANCE SHEET IN HIGH SCHOOL RENEWAL

DOI: $10.22481 /$ rbba.v1i02.7795

Patricio Grande

Universidad Nacional de Luján, Argentina Dirección electrónica: patriciogrande@yahoo.com.ar

Natalia Wiurnos

Universidad Nacional de Luján, Argentina Dirección electrónica: natywiurnos@hotmail.com

Matías Bidone

Universidad Nacional de Luján, Argentina Dirección electrónica: matias-bidone@ hotmail.com

\section{RESUMEN}

El artículo presenta una serie de conclusiones investigativas tendientes a la construcción de un balance en torno a la renovación de la asignatura historia en la escuela secundaria. Para ello se recuperan y analizan diversos ejes, tales como: el lugar asignado a las clases y grupos subalternos; el peso curricular de lo contemporáneo y la cuestión del eurocentrismo; $\mathrm{y}$, los nuevos enfoques sobre la llamada historia colonial americana. En líneas generales las renovaciones curriculares 
operadas en Argentina desde la década de 1990, en particular las ocurridas en la provincia de Buenos Aires, mostraron modificaciones significativas en la tradición escolar de este país $\mathrm{y}$ propusieron un acercamiento hacia las preocupaciones y el desarrollo de la historia investigada o académica. El interrogante central de este trabajo es: ¿Cuán profundas fueron estas modificaciones?

Palabras claves: Historia; Enseñanza; Escuela secundaria.

\title{
RESUMO
}

$\mathrm{O}$ artigo apresenta uma série de conclusões investigativas tendentes à construção de um balanço em torno à renovação da disciplina História no ensino médio. Para isso, são recuperados e analisados diversos eixos, tais como: o lugar atribuído às aulas e grupos subalternos; o peso curricular do contemporâneo e a questão do eurocentrismo; e as novas abordagens sobre a chamada História Colonial Americana. Em linhas gerais, as renovações curriculares operadas na Argentina desde a década de 1990, em particular as que ocorreram na província de Buenos Aires, mostraram modificações significativas na tradição escolar deste país e propuseram uma aproximação às preocupações e o desenvolvimento da história tanto em pesquisas quanto no âmbito acadêmico. O interrogante central desse trabalho é: ¿quão profundas seriam essas modificações?

Palavras-chave: História; Ensino; Ensino médio.

\begin{abstract}
This article explains a sequence of investigative conclusions tending to build a balance sheet about the history subject renovation in high school. To do this balance, different central concepts were reviewed and analyzed, such as: the place assigned to subordinate classes and groups; the curricular weight of the contemporary time and Eurocentrism issue and the new approaches in the American colonial history. In general terms, the curricular renovations which have operated in Argentina since the 1990s, in particular in the province of Buenos Aires, have showed significant modifications in the school tradition of this country. In addition these changes have proposed an approach towards the concerns and development of the investigated or academic history. The central question of this work is: How deep are these modifications?
\end{abstract}

Keywords: History; Teaching; High school.

\section{INTRODUCCIÓN}


La propuesta de este artículo consiste en divulgar algunos de los resultados, conclusiones y aportes más significativos acerca un conjunto de desarrollos investigativos en torno a la enseñanza de la historia en Argentina, realizados en el Departamento de Educación de la Universidad Nacional de Luján ${ }^{\mathrm{i}}$. Estas recientes investigaciones (algunas en curso) ${ }^{\mathrm{ii}}$ abordan diversas problemáticas en torno a los actuales documentos curriculares oficiales de historia para el nivel secundario de la provincia de Buenos Aires, y también su correlato en las aulas escolares. Estas problemáticas sobre la enseñanza de la historia en el presente, ancladas en una región geográfica determinada, son analizadas desde una perspectiva histórica que pone de relieve toda una larga construcción social de una disciplina escolar y, al mismo tiempo, su relación con la ciencia de referencia.

Con el propósito de intentar plasmar un relato polifónico y obtener una aproximación sobre lo que ocurre en algunas escuelas bonaerenses, el corpus central de fuentes estará constituido por una variada documentación: Diseños Curriculares jurisdiccionales para historia, libros de texto escolares y materiales didácticos para la enseñanza de la historia, documentos orientadores oficiales, programaciones elaboradas por profesores/as de historia, entrevistas a docentes vinculados con la enseñanza de la historia y observaciones áulicas ${ }^{\text {iii }}$

Cabe señalar que, debido a la gran diversidad de situaciones, la cantidad de docentes y escuelas que la jurisdicción provincia de Buenos Aires contiene, las conclusiones relativas a la implementación de las nuevas disposiciones y contenidos curriculares y a las propias prácticas docentes abordadas, no pueden ser consideradas como representativas del quehacer del conjunto de las y los profesores de enseñanza media bonaerense, ni siquiera de un sector mayoritario del mismo. Por ello las reflexiones y conclusiones relativas a ello se presentan aquí solo en calidad de planteos ilustrativos de algunas situaciones y cuestiones que se quieren destacar y que se han podido advertir, quitándole toda pretensión de representatividad o alcance general.

Para llevar adelante esta propuesta de trabajo se desarrollarán a lo largo del artículo cuatro ejes centrales que intentan sintetizar las principales temáticas investigadas, en pos de problematizar diversas dimensiones curriculares del conocimiento histórico escolar: en primer lugar, se presenta una sucinta vista panorámica en perspectiva histórica sobre la enseñanza de la historia en Argentina, desde las últimas décadas del siglo XIX hasta el presente; en segundo lugar, se examina la presencia de la historia contemporánea y la cuestión del eurocentrismo; en tercer lugar se desarrollan algunas líneas de análisis sobre el tratamiento otorgado a las clases 
LA ENSEÑANZA DE LA HISTORIA EN LA PROVINCIA DE BUENOS AIRES:

APORTES PARA LA CONSTRUCCIÓN DE UN BALANCE SOBRE SU RENOVACIÓN

EN LA ESCUELA SECUNDARIA

y grupos subalternos en la "Nueva Escuela Secundaria"; y por último, se presentan una serie de conclusiones sobre el tratamiento escolar de la llamada "historia colonial americana".

\section{Un siglo y medio de enseñanza de la historia en las escuelas secundarias: del "eterno" relato estatalista-nacionalista a la una renovación (parcial) de los contenidos}

Gonzalo De Amézola arriba a la conclusión de que en Argentina el nacionalismo fue el objetivo primordial de la historia en la escuela desde el momento de su instalación, hacia fines del siglo XIX, hasta por lo menos la reforma educativa de 1993. Un nacionalismo que, señala este autor, fue mutando "desde su interés por cohesionar ideológicamente a la nación frente a la llegada de los inmigrantes a un particular culto a la patria para justificar el protagonismo de los militares (...) y una defensa del autoritarismo" (2008, p. 51).

Así, en las últimas décadas del 1800 se instituyó en las escuelas de este país un relato de características teleológicas sobre el pasado nacional. Un pasado plagado de certezas, sin fisuras narrativas e interpretativas, donde la idea de nación se suponía previa a la existencia de las naciones mismas y a los Estados nacientes como resultado de las prolongadas guerras de independencia en América. Es decir que desde arriba, a través de las distintas esferas del poder estatal, se construyó una idea y un discurso hegemónico sobre la nación como una suerte de entidad autónoma que se colocaba por encima de la voluntad de los individuos. En sus comienzos este relato escolar estuvo asociado a las grandes obras de la historiografía liberal, específicamente a las producciones de Bartolomé Mitre.

Para materializar estos postulados se utilizaron una serie de rituales patrióticos o cívicos. Por ejemplo, la construcción de efemérides como el 25 de mayo de 1810 y el 9 de julio de 1816 y la exaltación de héroes como modelos positivos para ser imitados por las y los jóvenes. Desde comienzos del siglo XX esas fechas se fijaron, año tras año, como mojones temporales (acontecimientos) que establecieron momentos fundacionales de esa nación mítica.

A partir de la década de 1960 el campo historiográfico en Argentina se profesionalizó definitivamente: se pusieron en práctica nuevos criterios interpretativos e historiográficos incorporando a sus estudios históricos aportes de otras ciencias sociales y se fue "desnacionalizando" a partir de modificar, ampliar y/o revisar sus intereses y preguntas de investigación. Sin embargo, los contenidos escolares se mantuvieron (al menos desde lo 
LA ENSEÑANZA DE LA HISTORIA EN LA PROVINCIA DE BUENOS AIRES:

APORTES PARA LA CONSTRUCCIÓN DE UN BALANCE SOBRE SU RENOVACIÓN

EN LA ESCUELA SECUNDARIA

regulado por el propio Estado) prácticamente sin variaciones y alejados de los intereses de las/os de historiadores profesionales.

Así, desde la segunda mitad del siglo XX "historia académica" e "historia enseñada" se convirtieron en dos campos escindidos: mientras que el campo investigativo se profesionalizó, la historia escolar se consolidó como una disciplina de conocimientos autónoma con sus propias reglas cuya característica central fue la perdurabilidad de los contenidos enseñados o regulados oficialmente. Con el correr de las décadas la historia enseñada se transformó y consolidó como una disciplina autónoma y relativamente independiente de la "historia-ciencia". Para ello se valió de sus propias reglas, saberes y prácticas escolares: una tradición selectiva de sus contenidos, cuyo núcleo básico seguía siendo el relato único "Estado-nacióncentrista" y donde los grupos subalternos y los antagonismos sociales se encontraron huérfanos de toda representación en el currículo. A este saber escolar diferenciado y autónomo Raymundo Cuesta Fernández lo denominó, en su estudio del caso español, conceptualmente como "código disciplinar" (1997).

Con esas características generales la enseñanza escolar de la historia se acercaba a las postrimerías del siglo XX. En un estudio comparativo con otras asignaturas escolares realizado por Finocchio, la autora llegaba a la siguiente conclusión: "la historia se caracteriza por un prolongado retraso en relación con la disciplina científica, y por su escasa respuesta actual a lo que demanda la sociedad de este saber" (1991, p. 52).

La renovación curricular ocurrida en Argentina desde la década de 1990, resultante de dos reformas educativas nacionales (1993 y 2006), mostró modificaciones en la tradición escolar de este país y propuso un acercamiento hacia las preocupaciones de la historia investigada. En esta línea María Paula González plantea que los contenidos actuales son más complejos, muestran un acercamiento a la historiografía, aparecen nuevos conceptos y fuentes, se describen procesos y no acontecimientos desde una perspectiva latinoamericana y "se incluye el estudio de grupos sociales históricamente invisibilizados o postergados (indígenas, mujeres, sectores populares) hasta hace poco tiempo" (2016, p. 5).

Específicamente sobre los Diseños Curriculares para historia en la provincia de Buenos Aires, Edelstein (2015) explica algunas de las problemáticas historiográficas y los problemas de enseñanza que formaron parte de las preocupaciones e intenciones que orientaron su elaboración entre los años 2007 y 2012. Según este autor, los nuevos programas de historia, sobre la premisa de recuperar para el ámbito de la enseñanza los estudios históricos, se Revista RBBA $\mid$ Revista Binacional Brasil Argentina 
LA ENSEÑANZA DE LA HISTORIA EN LA PROVINCIA DE BUENOS AIRES:

APORTES PARA LA CONSTRUCCIÓN DE UN BALANCE SOBRE SU RENOVACIÓN

EN LA ESCUELA SECUNDARIA

orientaron sobre la base de cinco ejes centrales: el desarrollo temporal progresivo, es decir el descentramiento del gran relato occidental de la historia; la articulación de diferentes escalas geográficas; el carácter progresivo de los Diseños, mientras que para los primeros tres años de la escuela secundaria se centró en la enseñanza del tiempo histórico, el ciclo orientado $\left(4^{\circ}, 5^{\circ}\right.$ y $6^{\circ}$ año) lo hizo en la construcción del tiempo histórico; la introducción de sujetos sociales tanto individuales como colectivos desde la multivocidad y la multiperspectividad; y la multicausalidad.

Es decir que estos documentos curriculares introdujeron una serie de innovaciones pedagógicas e intentaron establecer una articulación entre la historia escolar y algunos de los desarrollos recientes de la historiografía. No obstante, se observa en ellos una cierta inconsistencia o contradicción entre algunos de los contenidos seleccionados y la fundamentación de la propuesta de enseñanza.

Lo que en rigor acontece con estos documentos circulares es una coexistencia entre algunas innovaciones y la permanencia de varios elementos selectivos de corte tradicional en la enseñanza de la historia. Es decir, que cohabitan en el presente contenidos canonizados por la tradición escolar, centrados en la mitología de un progreso ininterrumpido de matriz occidental y en un relato histórico cuyo núcleo central y articulador es el Estado-nacional. Ello habilita a una cierta pervivencia, aunque modificada y diluida, de los clásicos relatos positivistas/patrióticos. Al menos algunos jirones de ellos.

\section{La presencia de la historia contemporánea y la cuestión del eurocentrismo}

Una de las principales características que tuvo la renovación curricular ocurrida en Argentina a partir de la década de 1990 fue el marcado y paulatino énfasis puesto en la historia contemporánea y el pasado reciente de Argentina, que hasta ese momento no ocupaba un lugar de atención privilegiado entre los especialistas. Antes de la sanción de la Ley Federal de Educación $\mathrm{N}^{\circ} 24.195$ de 1993, la inclusión de contenidos relativos a los derechos humanos y su violación en períodos dictatoriales había sido dispuesta en diversas jurisdicciones por medidas legislativas y ejecutivas, principalmente referidas a algunas conmemoraciones escolares y, sobre todo, en relación a las asignaturas de educación cívica (GONZÁLEZ, 2016, p. 59-60). No obstante, fue la disolución de la amenaza militar al orden constitucional la que 
LA ENSEÑANZA DE LA HISTORIA EN LA PROVINCIA DE BUENOS AIRES:

APORTES PARA LA CONSTRUCCIÓN DE UN BALANCE SOBRE SU RENOVACIÓN

EN LA ESCUELA SECUNDARIA

allanó definitivamente el camino para una revisión curricular en función de su importancia para la legitimación de los gobiernos democráticos y la construcción de ciudadanía.

Paralelamente, se fue generalizando el cuestionamiento en torno al valor formativo de lo que se enseñaba y aprendía en la escuela. Así, se fue instalando la necesidad de incorporar saberes que estuvieran relacionados con los intereses de las y los jóvenes en la actualidad y, a la vez, fueran significativos desde el punto de vista de las preocupaciones de las distintas ciencias (DE AMÉZOLA, 2005, p. 71). El principal supuesto era que un mayor estudio de lo contemporáneo y lo reciente les permitiría a las y los estudiantes una mejor comprensión de su presente y la adquisición de herramientas que favorecieran su formación como ciudadanos democráticos, críticos y participativos.

A grandes rasgos, puede decirse que esta novedad se consolidó y profundizó con la ley educativa sancionada en $2006^{\text {iv }}$ y en los documentos curriculares de la provincia de Buenos Aires. La distribución de los contenidos para la asignatura historia entre primero y sexto año de la escuela secundaria muestra la primacía de la historia contemporánea y que el estudio del siglo XX es una de las propuestas centrales.

De manera esquemática, se podría decir que el $1^{\circ}$ año (asignatura "Ciencias Sociales") abarca temas que van desde los primeros hombres hasta finales del medioevo europeo; el $2^{\circ}$ año abarca el período que se corresponde con la "Edad Moderna"; en el $3^{\circ}$ año se aborda fundamentalmente el siglo XIX; en $4^{\circ}$ año la primera mitad del siglo XX y en $5^{\circ}$ año la segunda mitad. Para las orientaciones de Arte y Ciencias Sociales se incluye un año más de historia (en el $6^{\circ}$ año), dedicado al estudio del pasado reciente argentino. Como se puede observar, las y los jóvenes bonaerenses estudian la historia contemporánea durante la mayor parte de su trayectoria por el secundario.

Otra característica de los actuales Diseños Curriculares es el interjuego de escalas geográficas: mundial (fundamentalmente Europa), regional (Latinoamérica) y local (Argentina). De esta manera, los documentos curriculares hacen explicita la intención de abordar hechos y procesos históricos en el marco de un contexto espacio-temporal ampliado que permita la incorporación de diversas sociedades y formas de vida. La ambiciosa pretensión de incluir "muchos mundos" en el análisis histórico es particularmente evidente en el Diseño de $1^{\circ}$ año. Sin embargo, termina privilegiando la experiencia de construcción del occidente, con particular énfasis en el desarrollo de la división social del trabajo y las transformaciones del espacio europeo hacia la modernidad.

Revista RBBA $\mid$ Revista Binacional Brasil Argentina 
LA ENSEÑANZA DE LA HISTORIA EN LA PROVINCIA DE BUENOS AIRES:

APORTES PARA LA CONSTRUCCIÓN DE UN BALANCE SOBRE SU RENOVACIÓN

EN LA ESCUELA SECUNDARIA

En el Diseño de $2^{\circ}$ año se busca articular Europa occidental con Latinoamérica a través del concepto sistema-mundo, de Immanuel Wallerstein. Dicho concepto permite "abstraer del mundo real aquellas áreas del planeta que se encuentran vinculadas por una cierta lógica interna (en este caso de índole económica) para construir con ellos una unidad de análisis (un mundo) que se constituye como el objeto de estudio" (KUNTZ FICKER, 2014). Sin embargo, la propuesta curricular no está exenta de las dificultades que se presentan al intentar construir enfoques de escala mundial pues, en definitiva, Wallerstein se ocupa de un sistema-mundo en particular: la economía-mundo europea que inicia en el siglo XVI. Evidentemente, a pesar de otorgar una mayor importancia a los espacios extraeuropeos y hacer explícito el intento de superar los enfoques eurocéntricos (poniendo énfasis en la historia latinoamericana, profundizando aspectos relacionados al período colonial y la relación pasado-presente de esta región), este es un problema que los actuales Diseños no terminan de resolver. Por el contrario, se agudiza cuando abordan la época contemporánea, caracterizada por la expansión global de los modos de vida, sistema de valores y códigos culturales de occidente. A modo de ejemplo, se analizan las periodizaciones que estructuran los diseños curriculares de tercero, cuarto y quinto año.

El Diseño de $3^{\circ}$ año toma la periodización formulada por Eric Hobsbawn quien observa la existencia de un "largo siglo XIX" y un "corto siglo XX". Se busca encuadrar la propuesta curricular en el primero de los períodos (1776-1914), caracterizado por el triunfo del modelo burgués liberal con sus ideas de "nuevo orden" y progreso indefinido que condujeron a la denominada "Era del imperio", cuyas particularidades son la expansión ultramarina, la competencia entre las potencias, la concentración del capital y la llamada "división internacional del trabajo". No obstante, los procesos y hechos históricos regionales (Latinoamérica) y locales (Río de la Plata/Argentina) tienen preeminencia y buscan articularse con lo que sucede simultáneamente en Europa, que parece ocupar un lugar periférico y principalmente contextual.

Los Diseños de $4^{\circ}$ y $5^{\circ}$ año establecen un criterio de periodización que se sustenta en una escala de análisis amplia a nivel mundial y los contenidos están seleccionados, organizados y secuenciados siguiendo este criterio. De esta manera, se toma como marco general el período de entre guerras para el desarrollo del cuarto año (la "Era de las catástrofes", de acuerdo a la interpretación de Hobsbawm), y el mundo de posguerra, las luchas anticoloniales y los “Años 
LA ENSEÑANZA DE LA HISTORIA EN LA PROVINCIA DE BUENOS AIRES:

APORTES PARA LA CONSTRUCCIÓN DE UN BALANCE SOBRE SU RENOVACIÓN

EN LA ESCUELA SECUNDARIA

dorados" (de extraordinario crecimiento económico y transformación social, según Hobsbawm) para quinto año.

Sin embargo, como advierte Enzo Traverso (2016), no se debe perder de vista que la periodización que propone Hobsbawm es la fuerza de su obra y a la vez revela sus límites, puesto que las demarcaciones históricas seleccionadas por el autor no son generalizables a todas las partes del planeta. A modo de ejemplo, Traverso toma la experiencia histórica de África y observa la imposibilidad de considerar 1789 o 1914 como grandes inflexiones o virajes en la historia de este continente.

Como se puede observar, los Diseños Curriculares analizados proponen periodizaciones que organizan los contenidos de acuerdo a marcos interpretativos aceptados por el mundo académico, sin embargo, no escapan a las problemáticas que se presentan al momento de definir y establecer los hitos o marcas que configuran un período y le dan sentido. Ante la complejidad planteada, los Diseños de cuarto y quinto año advierten puntualmente sobre la dificultad de que los límites temporales establecidos se ajusten al desarrollo de los diferentes procesos históricos que, según la escala local o regional, pueden coincidir o no en una misma periodización (Diseño Curricular de $4^{\text {o }}$ Año, 2010, p. 10). De esta manera, la formulación de las unidades de sentido tempo-espacial propuestas, por cierto, necesarias para el abordaje de la realidad histórica en su conjunto (CIBOTTI, 2016, p. 38), contempla la flexibilización de los límites temporales de acuerdo a la escala de análisis latinoamericana o argentina (Diseño Curricular de $5^{\circ}$ Año, 2011, p. 10).

Ahora bien, tal como muestran múltiples investigaciones educativas, no existe una relación lineal entre las prescripciones normativas y las prácticas escolares. Entonces, cabe preguntarse: ¿de qué manera las propuestas curriculares son leídas y “apropiadas” por los y las docentes al momento de planificar sus cursos?.

Del análisis de un conjunto de veintidós programaciones de carácter anual de la materia historia $^{v}$, realizadas para cursos del $4^{\circ}$ y $5^{\circ}$ año durante los ciclos lectivos 2018 y 2019, se desprende que en catorce de ellas los contenidos se organizan y secuencian en unidades que responden a una periodización global estructurada por marcas temporales o hitos que hacen referencia a procesos históricos mundiales o europeos del siglo $\mathrm{XX}$, incluso el título de las mismas dan cuenta de ello ("El mundo en durante la Gran Guerra y la Revolución Rusa", "De la Primera guerra mundial a la Crisis del '30", "El mundo de posguerra", "La Guerra Fría", etc.). Llamativamente, esta particularidad se presenta incluso cuando se trata de unidades que 
abordan mayormente hechos y procesos históricos latinoamericanos y argentinos, de manera que los límites temporales no se flexibilizan de acuerdo la escala de análisis local o regional (que supondrían otras periodizaciones) y quedan subordinados principalmente a la experiencia histórica europea.

En los otros ocho casos (en los que se programa para cuarto año) los hechos y procesos correspondientes a la escala mundial se organizan y secuencian en las dos primeras unidades de la planificación (una que va de la Primera Guerra mundial hasta la Crisis del '30 y la otra que se extiende del ' 30 hasta el fin de la Segunda Guerra Mundial) y las dos unidades restantes abordan la historia Argentina desde las primeras presidencias radicales hasta el primer gobierno de Perón 1946-1952 inclusive, mientras que los acontecimientos y procesos de índole regional son prácticamente omitidos, contribuyendo al fortalecimiento de aquellos enfoques que tienden a considerar lo nacional como excepcional y básicamente incomparable con el resto de la región. Lo llamativo de estas últimas propuestas es la prácticamente nula articulación de escalas espaciales, así como la organización y secuenciación inconexa o fragmentada de las unidades de contenidos.

Desde ya, este análisis no pretende agotar el debate acerca de lo que ocurre en las escuelas bonaerenses en materia de enseñanza de la historia contemporánea. Por el contrario, cualquier abordaje que intente desentramar el fondo epistemológico que configura la clase de historia requiere de una multiplicidad de fuentes áulicas cuyo análisis excede los marcos de esta publicación.

\section{Las clases y grupos subalternos}

Antonio Gramsci fue el primer intelectual en otorgarle fuerza explicativa y densidad teórica al concepto de subalterno. Los escritos de Gramsci se transformaron en un mojón teórico y en una referencia ineludible para las y los historiadores luego de la Segunda Guerra Mundial. La enorme agenda de trabajo en torno las clases subalternas planteada por Gramsci fue recuperada y desarrollada por distintos grupos de historiadores/as.

En esa senda, cabe recuperar la experiencia de trabajo de la británica "historia desde abajo" desarrollada en los años de la segunda post-guerra. De vertiente teórica marxista o materialista histórica, fue impulsada desde la revista Past and Present fundada en 1952 y promovida durante las siguientes décadas por los historiadores Edward Thompson, Eric Revista RBBA $\mid$ Revista Binacional Brasil Argentina 
Hobsbawm, Rodney Hilton, George Rudé, Raphael Samuel y Christopher Hill, entre otros. Entre sus principales temáticas objeto de investigación se encontraban: el origen, desarrollo y expansión del capitalismo, la transición del modo de producción feudal al capitalismo, los orígenes de la clase obrera, la participación popular y la lucha de clases en la historia de Inglaterra.

Tal como plantea Hobsbawm en un ensayo escrito en 1985 (y reeditado en varias oportunidades), la historia desde abajo es la historia de la gente corriente (que constituye el grueso de toda sociedad) en "los momentos de excepcional movilización popular o durante la mayor parte del tiempo (...) Un aspecto importante de la historia desde abajo es lo que las personas corrientes recuerdan de los grandes acontecimientos a diferencia de lo que sus superiores piensan que deberán recordar" (2016, p. 210).

Empero, la obra de los marxistas británicos y particularmente la del propio Hobsbawm será años más tarde objeto de duras críticas. Estas críticas se centraron en el carácter teleológico y en el "modelo apriorístico" con el que se concebía a los agentes históricos presentes en sus trabajos investigativos (GONZÁLEZ, 2013, p. 12).

Hacia finales de la década de 1970 nació en la Universidad de Sussex (Inglaterra) el llamado Grupo o Escuela de los Estudios Subalternos del Sudeste Asiático (EES) quien intentó desplazar el foco de interés empírico, desde las clases hegemónicas hacia los grupos subalternos y rescatar así aquellas “voces negadas por los estatismos” colonial y nacional.

Las/os investigadores de la EES (Guha, Chatterjee, Prakash, Said, Gayatri, etc.) utilizaron la noción de subalternidad como categoría angular para el análisis histórico. Una categoría utilizada como "atributo general de subordinación (...) ya sea que esté expresando en términos de clase, casta, edad, género, ocupación o en cualquier otra forma" (GUHA, 1996, p. 23). El Grupo criticó los estudios realizados por la británica "historia desde abajo". Esas críticas se refirieron principalmente a su perspectiva eurocéntrica y a las explicaciones economicistas asociadas a los procesos de modernización. La obra de Hobsbawm fue particularmente criticada por el desarrollo de generalizaciones a partir de experiencias muy delimitadas en el tiempo y en el espacio y por considerar al campesinado como un actor pre-político, "carente de fines comunes y de organización” (TENTI, 2012, p.323). No obstante, cabe explicitar que el proyecto de la EES “fue inspirado, hasta cierto punto, por la 'historia desde abajo'; sin embargo, no fue una simple transmisión o importación de ideas o líneas iniciadas en otro lugar a la India, pues 
LA ENSEÑANZA DE LA HISTORIA EN LA PROVINCIA DE BUENOS AIRES:

APORTES PARA LA CONSTRUCCIÓN DE UN BALANCE SOBRE SU RENOVACIÓN

EN LA ESCUELA SECUNDARIA

la experiencia del colonialismo y la preocupación con la recién creada nación de India independiente, confirió al proyecto un carácter singular" (BANERJEE-DUBE, 2010, p. 101).

En nuestro continente hacia mediados de la década de 1990 se conformó el Grupo de Estudios Subalternos Latinoamericano, impulsado por un conjunto de científicos sociales (Beverley, Rodríguez, Rabasa, Carr, Seed, etc.) que asumieron el desafío de re-escribir un relato histórico capaz de interrumpir la teleología del Estado-nación y mostrar cómo la insurgencia de las clases subalternas interrumpe la narrativa de la formación estatal. Otro de sus anhelos era poder plasmar una clara separación entre los subalternos y el proyecto del Estado-nación.

Mientras que en Argentina existen recientes y diversos aportes historiográficos en torno a la "historia popular" o de "clases populares" en el ámbito rioplatense durante los siglos XVIII y XIX (Fradkin, Gelman, Garavaglia, Di Meglio, Ratto, etc.). Se trata de un conjunto de investigaciones en las que los sujetos comunes, de "carne y hueso", ocupan un lugar central. Algo relativamente novedoso en la historiografía argentina, sobre todo para la etapa colonial y el siglo XIX, ya que durante largo tiempo esos sujetos comunes quedaron invisibilizados u opacados, en el mejor de los casos, bajo la categoría abigarrada y anónima de "las masas".

Ahora bien, en torno a la enseñanza de la historia cabe preguntarse: ¿Cuál fue el impacto o la incidencia reciente que tuvieron estos desarrollos historiográficos en la historia escolar de Argentina? ${ }^{\mathrm{vi}}$

En los Diseños Curriculares para el "Polimodal"vii (elaborados en 1999 y 2004) se detectó una contradictoria coexistencia de algunas innovaciones, por ejemplo, la introducción de América Latina como un espacio histórico y geo-político central en el estudio de la historia, con la permanencia de elementos tradicionales como periodizaciones Estado-céntricas, conceptualizaciones, enfoques historiográficos sin antagonismos sociales y políticos visibles, etc. Si bien se pudo constatar la introducción en estos Diseños de algunos contenidos vinculados a experiencias políticas de grupos subalternos, en general éstos continuaron siendo actores sociales relegados en la enseñanza de la historia, ubicados en un lugar periférico.

Por su parte, en los programas de historia de la "Nueva Secundaria" (elaborados entre 2007 y 2012) se buscó establecer una articulación entre la "historia escolar" y algunos de los desarrollos recientes ocurridos en la órbita de la historiografía profesional. No obstante, cabe destacar que también los contenidos de estos Diseños, dicen poco acerca de la participación y la incidencia de las clases populares en diversos procesos históricos nodales, como ejemplo el 
largo proceso de construcción y consolidación del Estado nacional en el actual territorio argentino.

Por ejemplo, el Diseño Curricular del $3^{\circ}$ año se tituló "Historia de la expansión del capitalismo y de la formación de los Estados nacionales en América Latina”. Temporalmente abarca desde la "crisis del orden colonial en América" (fines del siglo XVIII) hasta la “organización de la Argentina Moderna" (inicios del siglo XX). La unidad de contenidos $\mathrm{N}^{0} 4$ (“Organización de la Argentina Moderna. Historia de contrastes”) se delineó sobre la base de cuatro ejes centrales: Organización del Estado moderno (en nuestro país), la transición al capitalismo en América Latina, el crecimiento de la economía agroexportadora en Argentina y la consolidación del poder económico de los sectores dominantes terratenientes. Al igual que en los Diseños preexistentes, en el "camino" hacia la consolidación del capitalismo y del Estado-nación, también aquí fue omitida la denominada "Campaña o Conquista al Desierto" en el actual sur argentino (1878-1885). Esta genocida empresa económica y militar quedó ahora subsumida bajo la denominación general de "la situación social en la frontera. Integración del territorio (...) [y] la colonización de las áreas vacías”.

También sobre este proceso histórico, centrado en la segunda mitad del siglo XIX a partir de la generalización y proyección del "caso argentino" hacia toda América Latina, en este Diseño se realizaron solo algunas acotadas menciones a grupos subalternos como "población de inmigrantes, chacareros, peones y jornaleros". Es decir que la participación y la incidencia de las clases populares en la conformación del Estado argentino, ya sea desde los "márgenes" o desde el "centro" mismo, es una problemática opaca en este programa.

De una muestra de diez libros de texto escolares analizados ${ }^{\text {viii }}$, correspondientes al Polimodal y la Nueva Escuela Secundaria, el balance general es que en la mayoría de ellos las clases populares ocupan un lugar de escasa relevancia, un hecho que imposibilita ensanchar la base de los conocimientos en historia. Según los relatos históricos predominantes en esos libros las blancas y occidentales clases dominantes, a través de una narrativa Estado-céntrica, son las protagonistas centrales de la historia. No obstante, un aspecto novedoso presente en todos los manuales examinados es el enfoque conceptual e historiográfico sobre la "cuestión de la nacionalidad". En cada libro (para conocer los libros analizados ver las referencias bibliográficas) se destinan algunas páginas para presentar a las naciones y las nacionalidades como parte de una construcción histórica propia del siglo XIX, procurando así cuestionar y desnaturalizar la idea de nación difundida en el siglo XX.

Revista RBBA $\mid$ Revista Binacional Brasil Argentina 
Además de esta documentación se incorporaron al análisis otras fuentes, con el propósito de obtener una aproximación sobre lo que ocurre en algunas escuelas bonaerenses y sobre las percepciones de enseñanza que tienen los propios docentes de historia. Se realizaron un conjunto de entrevistas a profesores/as de historia ${ }^{\text {ix }}$, de allí surge que si bien en los últimos años existen iniciativas para modificar las tradiciones de enseñanza, pervive en las escuelas (al menos en las instituciones/cursos donde se realizó el trabajo de campo) una tendencia de continuidad que se expresa o cristaliza en el dictado de contenidos consagrados/canonizados por esta disciplina escolar, centrados en la mitología del progreso racional/occidental y en la inevitabilidad histórica del Estado nacional. Como parte de esta misma problemática, los/as entrevistadas exponen que una "historia desde abajo" parece todavía una consigna pendiente. En esa línea de análisis varios docentes señalaron como un problema central la ausencia de una reflexión epistemológica sobre la historia y su enseñanza, tanto durante la formación de grado como durante el ejercicio profesional en instituciones escolares.

Además, se realizaron observaciones directas en clases de historia durante años recientes (2016-2017) en escuelas estatales de Luján y General Rodríguez. Como balance de esta esta pequeña muestra (compuesta por más de 20 clases) surge que existe una diversidad de situaciones y de escenarios en esta segunda década del siglo XXI. Se pudo constatar que existen en las aulas bonaerenses muchos contenidos, métodos y prácticas pedagógicas más bien tradicionales de la enseñanza historia que conviven, en tensión y contradicción, con algunas innovaciones metodológicas e historiográficas provenientes por ejemplo de la llamada nueva historia social, política y la historia "desde abajo".

Por ejemplo, dentro de este mosaico de experiencias se observan algunas (minoritarias) propuestas de trabajo elaboradas por los propios docentes que intentan poner en acción las innovaciones de la "historia popular rioplatense", con el objetivo de que los/as estudiantes conozcan y comprendan, por ejemplo, la composición social diversa de la población rural de la campaña de Buenos Aires y los cambios socio-económicos acaecidos durante el período revolucionario abierto desde 1810. Así, las clases y grupos populares de la campaña porteña ocupan un destacado lugar en la enseñanza: la población de origen africano, esclavizados, pastores, labradores, mano de obra asalariada, mujeres e indígenas.

Empero, y a modo ilustrativo, en otras programaciones y clases observadas en el $3^{\circ}$ año del ciclo común, se reproduce en las aulas un relato histórico de matriz "Estadonacióncentrista", donde el actual territorio argentino es presentado a los/as estudiantes como 
LA ENSEÑANZA DE LA HISTORIA EN LA PROVINCIA DE BUENOS AIRES:

APORTES PARA LA CONSTRUCCIÓN DE UN BALANCE SOBRE SU RENOVACIÓN

EN LA ESCUELA SECUNDARIA

una suerte de resultante de las constantes "pérdidas territoriales" respecto al antiguo territorio del Virreinato del Río de la Plata. Estos relatos históricos tienden a reproducir la concepción decimonónica sobre la formación de una "nación argentina" antes, incluso, de la crisis y del ciclo revolucionario abierto en 1810. También en esos relatos escolares del pasado prevalece una visión "desde arriba" de la historia nacional donde los acontecimientos, los procesos y las transformaciones son explicadas por las/os docentes desde las acciones políticas impulsadas y desarrolladas por un abanico de "grandes hombres" donde las clases populares serían una especie de mero instrumento político pasivo al servicio de los grupos sociales y políticos dominantes.

\section{4. La historia colonial americana ${ }^{x}$}

La historia colonial como parcela de estudio histórico fue sufriendo a lo largo de las últimas cuatro décadas una serie de renovaciones en sus enfoques y perspectivas historiográficas, a nivel continental y nacional. Miradas más complejas y ricas sobre el período minaron la producción historiográfica reciente y siguen proliferando estudios y debates de un sinfín de temas y problemas ligados a "lo colonial”. En línea con lo planteado anteriormente cabe preguntarse qué impacto tiene esta renovación historiográfica en la enseñanza de la historia en la actual secundaria. De esta manera, este apartado se concentra en el análisis de la enseñanza de la historia colonial, en particular el período histórico que va desde el siglo XVI hasta la llegada de las independencias en Hispanoamérica, estudiando qué formas de presentación de la historia colonial operan y se dan en la escuela.

Ahora bien, ¿por qué analizar la enseñanza de este período en particular? Se pueden argumentar tres elementos relevantes: por un lado, que las imágenes sobre el período colonial, sus costumbres y su sociedad son muy potentes y están muy presentes en la escolarización sobre todo primaria y muy ligadas a las efemérides y a los denominados "actos escolares" (en particular el "12 de octubre" y el "25 de mayo"). En ambas se ponen en juego miradas arquetípicas y estereotipadas de esta sociedad y las costumbres coloniales, retratando un tipo de sociedad en donde sus actores parecerían ser siempre los mismos, carentes de conflictos, intereses e incluso dinamismo (BARRAL, WIURNOS y GRANDE, 2017). Por ello es importante cuestionarse acerca de cómo operan estas imágenes ya en el nivel secundario es el momento donde las efemérides no están tan vinculadas a este tipo de escenificación.

Revista RBBA $\mid$ Revista Binacional Brasil Argentina 
Por otro lado, la etapa colonial se presentó muchas veces (tanto desde lo historiográfico como desde la enseñanza) como una suerte de "prehistoria" de las historias nacionales colocando mucho de los rasgos propios de tiempos posteriores y procesos históricos del siglo XIX en la sociedad colonial. Tal como se mencionó en acápites anteriores, una especie de mirada "finalista" o teleológica tiñó fuertemente a dicho período. Sin embargo, desde perspectivas más recientes de la producción historiográfica se postula a "lo colonial" como una etapa que posee características propias, cuyas sociedades fueron portadoras de lógicas, dinámicas y rasgos diferentes a los que se fueron gestando posteriormente (aun cuando las continuidades y las relaciones con etapas posteriores se puedan y deban establecer). Esta mirada contribuiría a complejizar la concepción sobre las sociedades del pasado colonial pero también de las del presente, tendiendo puentes entre la significativa huella del pasado colonial con los procesos de conformación de los Estados Nacionales hasta la actualidad sin que ello suponga realizar lecturas lineales y anacrónicas entre ambos procesos históricos.

Por último, la etapa colonial como período histórico a enseñar fue un eje de discusión y controversia en el marco de la renovación curricular de la década de 1990, que pretendía estar centrada en la historia de la sociedad occidental contemporánea, minimizando el estudio de aquellas sociedades y períodos previos al siglo XIX. Esta concepción está fuertemente ligada a una historiografía que ve el "comienzo" de la historia nacional a partir del último cuarto de 1800 con la llamada "Argentina Moderna" (modelo agroexportador, presidencias liberales, inmigración europea masiva, etc.). En este contexto, se alzaron voces disidentes que impugnaron esta perspectiva (FRADKIN, 1998) aunque en los hechos la reforma educativa de dicha década dejó documentos curriculares que indicaban la preeminencia de una enseñanza de la historia fundamentalmente contemporánea y occidental. Ahora bien, ¿qué sucedió al respecto con la nueva ley educativa sancionada en 2006 y los nuevos documentos curriculares de la provincia de Buenos Aires?

Abordar este vasto tema y período histórico en su totalidad puede resultar complejo y hasta confuso, por lo cual se optó por seleccionar ciertas variables o aspectos relacionados al mismo para enfocar el análisis, y en particular aquí se presentan algunas conclusiones sobre el estudio de una variable o arista relacionada al período: qué se enseña puntualmente sobre la sociedad colonial, específicamente a través de lo que prescriben los Diseños Curriculares y lo que plantean los libros de texto. También se procura avanzar sobre el examen de situaciones áulicas concretas que den cuenta de la enseñanza de esta etapa.

\begin{tabular}{l|l} 
Revista RBBA & Revista Binacional Brasil Argentina
\end{tabular} 
Primero se puede reseñar que la actual Escuela Secundaria brinda un año completo al estudio del período entre los siglos XV y XIX; el Diseño Curricular de $2^{\circ}$ año está vertebrado desde la relación entre Europa y América a partir de la conquista y tiene un mayor peso el abordaje de la historia colonial fundamentalmente latinoamericana. Esto representó una gran novedad respecto del menor peso presentado en Diseños Curriculares previos y tras el debate suscitado en el marco de la renovación de curricular los años ' 90.

En segundo lugar, cabe preguntarse cuál es el tratamiento que estos documentos realizan sobre la sociedad colonial: se puede concluir que en líneas generales procuran superar la clásica mirada "piramidal" (que de forma simplificada puede resumirse en la triada "españolesindígenas-esclavos") acercándose a perspectivas más actualizadas sobre la sociedad. Por ejemplo, se procura superar los estereotipos de "superioridad e inferioridad" que tiñen la relación entre los españoles y los indígenas, se apunta al análisis de las graves consecuencias de la invasión en las sociedades indígenas por ejemplo a través de la "catástrofe demográfica", se presenta como un aspecto importante a estudiar las resistencias indígenas y el planteo de la existencia de "intersticios contradictorios a las relaciones coloniales dominantes".

Muchos de estos aspectos están presentados en los fundamentos de las unidades de contenidos, aunque, cabe decirlo también, en la construcción de los contenidos en sí, algunos de estos aspectos se diluyen. Lo que marca una diferencia positiva es el planteo de una última unidad de contenidos que procura exponer un "enfoque integrado respecto a la construcción de las identidades étnicas en Latinoamérica" con el objetivo de "mostrar" el carácter histórico de las relaciones sociales que se construyeron y construyen en América Latina, enlazando así el vínculo entre pasado y presente. Se apela de esta manera a las raíces identitarias pre-hispánicas y coloniales, como pueden ser los aportes indígenas y afrodescendientes y el mestizaje.

En los libros de texto ${ }^{x i}$ también se observan enfoques más complejos a la hora de caracterizar y explicar la sociedad colonial. Se puede mencionar el intento por superar la mirada "piramidal” y explicando incluso la existencia de una diversidad dentro de los grupos sociales (por ejemplo, las desigualdades entre los jefes étnicos y los indígenas comuneros); aunque cabe aclarar que en general se siguen tomando como casos de estudio esquemas de sociedades relacionadas a los polos urbanos más importantes de la colonia (México y Lima) a los cuales se suma la sociedad porteña o rioplatense.

Otros temas significativos y disruptivos sobre el período y su sociedad se mencionan o trabajan pero no aún con suficiente énfasis o complejidad: como por ejemplo la esclavitud y los 
afrodescendientes, el mestizaje, las sociedades indígenas "no sometidas" y las mujeres. Allí queda trabajo pendiente por hacer. Por su parte, "las resistencias" al orden colonial (en sus múltiples formas: activas, pasivas, rebeliones, revueltas, simbólicas, etc.) fueron una constante durante este proceso histórico y actualmente la historiografía ha avanzado mucho en su conocimiento, no solo aquellas protagonizadas por los indígenas sino también por otros actores como esclavizados o mestizos. Sin embargo, los manuales presentan estos episodios como hechos aislados y excepcionales.

Finalmente, cabe interrogarse acerca de qué es lo que está sucediendo en las aulas con la enseñanza de la historia colonial. Se analizó una muestra de observaciones de clases de historia de $2^{\circ}$ año ${ }^{\text {xii }}$ que abordaron temas relacionados al período en estudio; su examen no pretendió conformarse en el reflejo directo de la realidad, sino que se procuró funcionar como motor que permita establecer relaciones con el análisis desarrollado hasta aquí y habilite nuevos interrogantes para posteriores instancias de estudio y análisis.

Las clases registradas versaron sobre diversos temas como colonización, conquista de América, colonialismo, e incluso alguna de las clases coincidió con el tratamiento de la efeméride del "12 de octubre: Día de la Diversidad Cultural". De esta forma, se pudo observar cierta paridad en el abordaje de temáticas más “tradicionales" o más "actualizadas": dentro de estas últimas se recuperaron aportes relacionados al enfoque del Diseño Curricular y, aunque tímidamente, ciertos aspectos de tendencias historiográficas recientes. Por ejemplo, rescatando la herencia indo-arfrodescendiente en Argentina y poniendo en cuestión aquella vieja premisa que versaba que los "argentinos descendemos de los barcos" (aludiendo a la inmigración europea de fines del siglo XIX); o vertebrando las clases de la conquista de América a partir de las múltiples resistencia de los actores sociales locales, poniendo en tensión la idea más clásica de "pasividad" de los indígenas frente a la invasión o de la "superioridad" hispana en relación a las sociedades originarias.

Sin embargo, también (y casi en igual proporción) otro conjunto de clases observadas presentó una perspectiva mucho más tradicional sobre la conquista y el proceso de colonización. En estas clases el abordaje del contenido no se vinculaba al Diseño Curricular ni presentaba un tratamiento problematizado; todo lo contrario, los contenidos apuntaban al tratamiento de hechos fácticos como por ejemplo los viajes de Colón, quién fue Martín Pinzón, la conquista por parte de Cortés, el Tratado de Tordesillas, etc. Es decir, el proceso de conquista era visto 
LA ENSEÑANZA DE LA HISTORIA EN LA PROVINCIA DE BUENOS AIRES:

APORTES PARA LA CONSTRUCCIÓN DE UN BALANCE SOBRE SU RENOVACIÓN

EN LA ESCUELA SECUNDARIA

desde los conquistadores y desde un enfoque absolutamente fáctico, tradicional y enciclopedista.

En síntesis, puede afirmarse que el análisis de este conjunto de clases de historia mostró que en líneas generales se está manifestando una convivencia entre miradas y perspectivas muy problematizadoras y ligadas a actualizaciones historiográficas con otras que, aún, exponen relatos más bien tradicionales de la mano de temas bien "clásicos".

\section{CONCLUSIONES}

A lo largo del artículo se buscó presentar y problematizar algunas conclusiones investigativas (en base a la exploración y al análisis de distintos ejes temáticos y fuentes escolares) tendientes a realizar diversos aportes que abonen a la elaboración de un balance sobre la renovación ocurrida en la enseñanza de la historia en la escuela secundaria. En base a la documentación y los casos analizados aquí, es posible concluir que en líneas generales las renovaciones curriculares ocurridas en la provincia de Buenos Aires desde los años '90, mostraron algunas importantes modificaciones o transformaciones en que intentaron trastocar a toda una larga tradición escolar en enseñanza de la historia en las escuelas secundarias. Estas transformaciones se realizaron sobre la intención de lograr un acercamiento hacia las preocupaciones y los desarrollos de la historia investigada o académica. Fue así como, en líneas generales, se procuró dejar atrás el "eterno" relato estatalista-nacionalista.

Una de las principales características que tuvo la (parcial) renovación curricular bonaerense fue el marcado énfasis que se colocó en la historia contemporánea, particularmente el siglo XX, y en el pasado reciente de Argentina. También en las líneas de este artículo se mostró que los actuales Diseños buscan otorgar una mayor importancia a los espacios geopolíticos-culturales extraeuropeos (fundamentalmente América Latina), a partir de la articulación de escalas geográficas, y procurar así superar los clásicos enfoques eurocéntricos. Sin embargo, este problema no se terminó de resolver completamente.

A pesar de este fuerte sesgo presentista existente en los actuales currículos oficiales bonaerenses, se pudo observar que la enseñanza de la historia colonial americana (en tanto parcela específica de estudios históricos) muestra interesantes y renovados enfoques tendientes a superar las clásicas miradas o relatos estereotipados en torno a la "superioridad e inferioridad"

que tiñen las relaciones sociales entre españoles e indígenas. Por el contrario, en los nuevos

\begin{tabular}{l|l} 
Revista RBBA & Revista Binacional Brasil Argentina
\end{tabular} 
LA ENSEÑANZA DE LA HISTORIA EN LA PROVINCIA DE BUENOS AIRES:

APORTES PARA LA CONSTRUCCIÓN DE UN BALANCE SOBRE SU RENOVACIÓN

EN LA ESCUELA SECUNDARIA

documentos se introdujeron algunos interesantes intersticios que buscan poner bajo tensión y contradicción a las relaciones coloniales dominantes.

Empero, es necesario destacar que junto con estos elementos de renovación coexisten contenidos canonizados por la ("eterna") tradición escolar donde prevalece un tipo de relato histórico cuyo núcleo central y articulador es el Estado-nacional. Asimismo, los actuales documentos educativos dicen poco acerca de la participación y la incidencia de las clases populares en diversos procesos históricos. Algo similar, se puede observar en la mayoría de los libros de texto escolares analizados aquí donde las clases populares o grupos subalternos ocupan un lugar de escasa relevancia y permanecen invisibilizados. Un hecho que sin dudas imposibilita ensanchar la base de los conocimientos y la compresión de la historia.

Por último, el análisis de la pequeña muestra regional o local con entrevistas a profesores/as de historia en ejercicio, de sus planificaciones y de las clases parece mostrar que, en al menos algunas de las aulas bonaerenses prevalecen aún muchos contenidos, métodos y prácticas pedagógicas de un corte más bien tradicional de la enseñanza historia. No obstante, esas pervivencias existen allí en tensión y contradicción con algunas innovaciones metodológicas e historiográficas provenientes por ejemplo de la llamada nueva historia social y la historia "desde abajo". De esta forma, las modificaciones o transformaciones operadas en el nivel curricular e institucional, a pesar de todas las limitaciones expuestas, se traducen de manera lenta o tardía en las planificaciones y en las clases. Como hipótesis abierta, se podría ensayar que este hecho mostraría la existencia de una larga y desacompasada transición en curso hacia nuevas formas y contenidos en la enseñanza de esta disciplina escolar. En este sentido la enseñanza de la historia en esta región de Argentina se encontraría en medio un proceso abierto donde, parafraseando al maestro Antonio Gramsci, "lo viejo no termina de morir y lo nuevo no termina de nacer". 
LA ENSEÑANZA DE LA HISTORIA EN LA PROVINCIA DE BUENOS AIRES:

APORTES PARA LA CONSTRUCCIÓN DE UN BALANCE SOBRE SU RENOVACIÓN

EN LA ESCUELA SECUNDARIA

\section{REFERENCIAS}

AMÉZOLA DE, G. Los historiadores proponen cómo cambiar la enseñanza: la reforma educativa argentina en las Fuentes para la transformación curricular. En Revista de Teoría y Didáctica de las Ciencias Sociales, Mérida, Venezuela, Universidad de los Andes, n. 10, enero-diciembre, p. 67-99, 2005.

AMÉZOLA, G. DE. Esquizohistoria. La Historia que se enseña en la escuela, la que preocupa a los historiadores y una renovación posible de la historia escolar. Buenos Aires: Libros del Zorzal, 2008, 130p.

BARRAL, M. E., WIURNOS, N., GRANDE, P. ¿Qué historia cuentan los actos escolares?. La Educación en Debate, Buenos Aires, UNIPE agosto 2017, n. 53.

BANERJEE-DUBE, I. Historia, Historiografía y Estudios Subalternos. En ISTOR, año 11, no 41, p. 99-118, 2010.

BUENOS AIRES (Provincia). Dirección General de Cultura y Educación. Diseños Curriculares para la educación secundaria. La plata, Buenos Aires, 2007-2012.

CIBOTTI, E. América Latina en la clase de historia. Bs. As.: Editorial Fondo de Cultura Económica, 2016.

CUESTA FERNÁNDEZ, R. Sociogénesis de una disciplina escolar: la historia. Barcelona: Ediciones Pomares Corredor, 1997.

EDELSTEIN. E. Aproximaciones a los Diseños curriculares y a la historia enseñada en Escuela Secundaria de la Provincia de Buenos Aires". En: VI Jornadas de la División Historia - III Taller de Historia Regional. Universidad Nacional de Luján, 2015.

FINOCCHIO, S. ¿Qué llega de nuestra investigación a la escuela media? En Entrepasados, Buenos Aires, n. 1, p. 93-106, 1991.

FRADKIN, R. Enseñanza de la historia y reforma educativa. Algunas reflexiones críticas sobre los Contenidos Básicos Comunes. En Anuario IEHS, Tandil, Buenos Aires, n.13, p. 310-317, 1998.

GONZÁLEZ, R. Eric J. Hobsbawm, la Historia desde abajo y el análisis de los agentes históricos. En Rubrica Contemporánea, nº 4, p. 5-22, 2013.

GONZÁLEZ, M. La historia escolar a inicios del siglo XXI: cambios, pérdidas y conquistas. En Sociohistórica, Universidad Nacional de La Plata, Buenos Aires, n. 37, p. 1-15, 1er. semestre 2016.

GRANDE, P. Los grupos subalternos y las clases populares en la enseñanza de la historia en Argentina. Relaciones bajo tensión entre las producciones historiográficas y las innovaciones de la historia escolar bonaerense". En Polifonías Revista de Educación, Luján, Buenos Aires, año VII, n. 15, p. 26-54, 2019. 
LA ENSEÑANZA DE LA HISTORIA EN LA PROVINCIA DE BUENOS AIRES:

APORTES PARA LA CONSTRUCCIÓN DE UN BALANCE SOBRE SU RENOVACIÓN

EN LA ESCUELA SECUNDARIA

GONZÁLEZ, M. La historia reciente en la escuela. Saberes y prácticas docentes en torno a la última dictadura. Bs. As.: Prometeo, 2014.

GUHA, R. Prefacio a los Estudios de la Subalternidad. Escritos sobre la Historia y la Sociedad Surasiática. En: Estudios de la Subalternidad Escritos sobre la Historia y la Sociedad Surasiática, Barcelona: Crítica, 1996.

HOBSBAWM, E. Sobre la historia desde abajo. En: Sobre la historia. Barcelona: Crítica, 2016, p. 205-219.

KUNTZ FICKER, S. Mundial, trasnacional, global: Un ejercicio de clarificación conceptual de los estudios globales. En Mundo Mundos Nuevos. Débats, mis en ligne le 27 mars 2014. Disponible en: http://journals.openedition.org/nuevomundo/66524; $\quad$ DOI : https://doi.org/10.4000/ nuevomundo.66524

TENTI, M. Los Estudios Culturales, la Historiografía y los sectores subalternos. En Trabajo y Sociedad, n. 18, p. 317-329, 2012.

TRAVERSO, E. Fin de siglo. El siglo XX de Eric Hobsbawm. En: La historia como campo de batalla: interpretar las violencias del siglo XX, Buenos Aires: FCE, 2016. Cap. 1, p. 3570 .

\section{Manuales escolares}

- Sobre las clases y grupos subalternos:

FRADKIN, R. (coord.). Historia. El mundo contemporáneo. Siglos XVIII, XIX y XX. Buenos Aires: Estrada, 2005.

FRADKIN, R. (coord.). Historia de la Argentina. Siglos XVIII, XIX y XX. Buenos Aires: Estrada, 2000.

DEVOTO, F., CHIRAMAONTE, J. (Dir.) H1. Historia argentina y latinoamericana 1. Buenos Aires: Tinta Fresca, 2006.

CASOLA, N. et. al. Historia. Argentina, América y Europa durante los siglos XVIII y XIX. Buenos Aires: Santillana, 2015.

GALleGO, M. et. al. Historia Latinoamericana en el contexto mundial. Buenos Aires: Editorial Maipue, 2007.

DEVOTO, F. (Dir.) y MÍGUEZ, E. (Coord.). H2. Historia argentina y latinoamericana 2. Buenos Aires: Tinta Fresca, 2009.

MÉREGA, H. (Dir.). Historia del mundo contemporáneo. Buenos Aires:

Ediciones Santillana, 2009.

$$
\text { Revista RBBA } \mid \text { Revista Binacional Brasil Argentina }
$$


RIZZI, A. et. al. Una Historia para pensar. La Argentina en el "largo siglo XIX" [en el contexto mundial y latinoamericano]. Buenos Aires: Kapelusz Editora, 2009.

TATO, M. et. al. Historia. La segunda mitad del siglo XX. Buenos Aires: Estrada, 2011.

TATO, M. et. al. Historia. El período de entreguerras. Buenos Aires: Estrada, 2015.

\section{- Sobre el período colonial:}

ALCOBRE, M. et. al. Historia 2. América y Europa (siglos XV-XVIII). Bs. As.: Tinta Fresca, 2015

BARRAL, M. E. (coord.) Saber de Historia. EI mundo americano hasta las independencias. Europa entre el siglo XV y mediados del XIX. Bs. As.: Eudeba-Ediba, 2012.

CASOLA, N. et. al. Historia. América y Europa en el siglo XIV y fines del siglo XVIII. Bs. As.: Santillana, 2015.

EGGERS BRASS, T. Y GALlEGO, M. Historia II. América indígena y la expansión europea. Bs. As.: Maipue, 2009.

MUSA, M. (coord.) Activados. Historia 2. Bs. As.: Puerto de Palos, 2016.

\section{Notas}

i Tesis de posgrados, proyectos de investigación, artículos y ponencias realizadas en el marco de las actividades de investigación del equipo docente de las asignaturas "Residencia y Práctica de la enseñanza de la Historia" y "Didáctica General y Especial de la Historia" de la carrera de Profesorado en Historia de la Universidad Nacional de Luján. Para mayor información sobre las investigaciones consultar: http://www.didacticadelahistoria.unlu.edu.ar/?q=node/13

ii Por ejemplo, el proyecto de investigación denominado "Los grupos subalternos en la enseñanza de la historia. Balances y horizontes para una renovación de la historia en la actual escuela secundaria bonaerense", radicado en el Departamento de Educación de la Universidad Nacional de Luján (Director: Patricio Grande).

iii Las fuentes escolares (como planificaciones docentes, entrevistas y observaciones áulicas) fueron tomadas en escuelas públicas y privadas pertenecientes principalmente a los distritos bonaerenses de Luján y General Rodríguez, ambos incluidos en la Región Educativa $\mathrm{n}^{\mathrm{o}} 10$ de la provincia de Buenos Aires.

${ }^{\text {iv }}$ La Ley de Educación Nacional ( $\mathrm{N}^{\circ}$ 26.206) estableció por primera vez en Argentina el carácter obligatorio del nivel medio o secundario.

${ }^{v}$ En este caso como en los próximos, tanto las planificaciones para la asignatura historia como las observaciones áulicas corresponden a escuelas situadas en los distritos bonaerenses de Luján y General Rodríguez.

vi Se presentan en esta parte algunas conclusiones investigativas del Trabajo Final para la carrera de Especialización en Cs. Sociales con mención en Historia Social de la Universidad Nacional de Luján. Autor: Patricio Grande. Tutora: M. E. Barral. Título: "La subalternidad en la enseñanza de la historia: clases populares, alteridad y antagonismos. La historia en la educación media en Argentina desde finales del siglo XX hasta principios del siglo XXI". Aprobada en 2018. Una primera síntesis de esta investigación fue publicada en: GRANDE, 2019.

vii Denominación que le otorgó la reforma educativa de los '90 a la educación media (compuesta por 3 años de duración de carácter no-obligatorio). 
viii Para realizar la selección de los manuales escolares se establecieron una serie de criterios: autoría y/o coordinación realizada por autoras/es vinculados con ámbitos investigativos como universidades nacionales y organismos científicos; circulación amplia entre docentes y estudiantes de las escuelas bonaerenses; y materiales producidos por empresas editoriales que sostengan en el tiempo una "tradición" en la elaboración de estos materiales educativos.

ix Se construyó un guión de entrevista compuesto de cuatro interrogantes centrales. Las preguntas fueron respondidas individualmente por diez profesores/as de historia que se desempeñaban como docentes de escuelas secundarias de Luján y General Rodríguez. Las preguntas realizadas fueron las siguientes: "¿Cuál te parece que debería ser la finalidad central de la enseñanza de la historia en la escuela secundaria en el siglo XXI?”; “¿Qué función/es cumple en la actualidad la historia en la escuela secundaria? y si ¿Se ha modificado, en lo substancial, su tradicional función escolar destinada a fomentar una conciencia cívica/patriótica o nacionalista?”; “¿Qué puntos de contactos y fracturas o tensiones existen hoy entre la llamada 'historiografía profesional' y la 'historia que se enseña' en las escuelas secundarias de la provincia de Buenos Aires?”; y “¿Qué lugar se les asignó en los últimos años a los grupos y clases subalternas en los contenidos de historia?"

${ }^{*}$ Se recogen aquí algunas de las principales conclusiones arribadas en el Trabajo Final de investigación para la carrera de Especialización en Cs. Sociales con mención en Historia Social de la Universidad Nacional de Luján. Autora: Natalia C. Wiurnos. Tutora: M. E. Barral. Título: "La enseñanza de la historia en la escuela secundaria de la provincia de Buenos Aires. Aportes y balances desde la historiografía colonial". El Trabajo Final completo puede consultarse en el Repositorio Digital Institucional de Acceso Abierto de la Universidad Nacional de Luján. Disponible en: https://ri.unlu.edu.ar/xmlui/handle/rediunlu/374

${ }^{x i}$ La muestra analizada fue de cinco manuales, todos ellos editados bajo el marco curricular vigente, y los criterios de selección fueron los mismos que los citados en el apartado previo. Para conocer los libros analizados ver las referencias bibliográficas.

xii Se analizaron un conjunto de observaciones áulicas (25 hs.) realizadas durante el ciclo lectivo 2017 en escuelas públicas y privadas (7 en total) de las Regiones Educativas No 8, 9, 10 y 13 de la provincia de Buenos Aires. 